\title{
CONE ERG SUBNORMALITY TO RED FLASH IN CENTRAL RETINAL VEIN OCCLUSION: A PREDICTOR OF OCULAR NEOVASCULARISATION?
}

\author{
MONIQUE S. ROY ${ }^{1}$, CYNTHIA J. MACKAY ${ }^{2}$ and PETER GOURAS \\ Newark, New Jersey and New York
}

\begin{abstract}
SUMMARY
In patients with unilateral central retinal vein occlusion (CRVO), we retrospectively examined whether cone electroretinogram (ERG) subnormality to red flash (ratio of the b-wave amplitude in the CRVO eye to that in the normal fellow eye $<1$ ) found at the time of diagnosis of the CRVO was a predictor of later ocular neovascularisation. Ganzfeld ERG cone and rod responses had initially been obtained in a consecutive series of 21 patients with unilateral CRVO. Patients were re-evaluated $6-55$ months later to determine whether ocular neovascularisation had developed. Of the 21 CRVO eyes, $6(29 \%)$ were subnormal to red in the affected compared with the normal fellow eye. At follow-up, all $6(\mathbf{1 0 0} \%)$ patients had developed ocular neovascularisation compared with $1(7 \%)$ of the 15 patients who were supernormal to $\operatorname{red}(p=0.00013)$. Cone ERG subnormality to red flash in CRVO eyes compared with normal fellow eyes may be a predictor of later development of ocular neovascularisation.
\end{abstract}

Central retinal vein occlusion (CRVO) is a common retinal disease. ${ }^{1}$ Follow-up studies of patients with CRVO have shown that $20-30 \%$ of patients may develop neovascularisation of either the iris, the anterior chamber angle or optic nerve. ${ }^{1-4}$ The stimulus for anterior segment and retinal neovascularisation, although poorly understood, is thought to be related to severe retinal ischaemia. 5 For those patients with iris neovascularisation, early panretinal laser photocoagulation is effective in causing ocular neovascularisation to regress, while delayed photocoagulation usually results in a painful blind eye. ${ }^{6-10}$

\footnotetext{
From: ${ }^{1}$ UMDNJ-New Jersey Medical School, Department of Ophthalmology, Newark, New Jersey; ${ }^{2}$ Department of Ophthalmology, Columbia University, New York, New York, USA.

Correspondence to: Dr Monique Roy, UMDNJ-New Jersey Medical School, Department of Ophthalmology, 90 Bergen Street, Suite 6164, Newark, NJ 07103-2499, USA. Fax: +1 (201) 982-2068.
}

Various clinical, ${ }^{11}$ angiographic ${ }^{5,12}$ and electroretinographic ${ }^{13-18}$ parameters have been used to predict which patients are at risk of developing ocular neovascularisation. However, none of them has been shown to be either sensitive or specific enough to identify all CRVO eyes in which neovascularisation will develop.

We have previously reported that in most patients with CRVO, the amplitude of the cone electroretinogram (ERG) b-wave is larger in the affected compared with the unaffected eye if the retina is sufficiently light-adapted and the test stimuli are of long wavelength. ${ }^{19}$ We have called this 'supernormality to red'. This supernormality is unexpected since CRVO has usually been reported to decrease the amplitude of the flash ERG. ${ }^{13-15,18,20,21} \mathrm{We}$ also observed that a minority of CRVO eyes, however, do not show this ERG supernormality to red flashes. In fact, they are subnormal to red in the affected compared with the unaffected eye, i.e. the ratio of the cone ERC b-wave amplitude to red in the CRVO eye to that in the normal fellow eye was less than 1 . In order to further elucidate the significance of differences in cone ERG responses to red in CRVO eyes, we decided to do a follow-up study of patients who had undergone an ERG at the time of diagnosis of the vein occlusion. We hypothesised that CRVO eyes which showed cone ERG subnormality to red flash compared with normal fellow eyes (ratio <1) would later develop ocular neovascularisation. The purpose of this paper is to report our findings.

\section{SUBJECTS AND METHODS}

Included in the study was a consecutive series of patients with unilateral CRVO and no abnormality of the fellow eye recruited from among patients either attending the general or retina clinics or referred by private physicians for an ERG. At the time the ERG was obtained, none of the patients had any evidence of neovascularisation of either the 
anterior or posterior segment and none of them had received either photocoagulation or cryotherapy. The diagnosis of CRVO was made by clinical examination if retinal venous dilation and retinal haemorrhages in all four retinal quadrants were present, with or without either cotton wool spots or macular oedema. In all patients, best corrected vision, intraocular pressure, undilated anterior segment and dilated fundus examination were obtained. The presence of either glaucoma, diabetes or known systemic hypertension was recorded.

In all patients, the ERGs were recorded simultaneously from both eyes using Burian-Allen bipolar contact-lens electrodes (Hansen Ophthalmic, Iowa City, IA). The cornea was anaesthetised and the pupil dilated to approximately $8 \mathrm{~mm}$ in diameter. The subjects sat with the head supported on a chin rest and looked into the ganzfeld sphere. The ERG was detected with a Nicolet (Madison, WI) CA-1000 and more recently a Viking $2 \mathrm{~A}$ and Spirit signal averager coupled to a ganzfeld stimulator providing relatively strong adapting fields (15000 trolands).

The adapting light originated from a halogen projector lamp and its luminance produced on the white interior of the ganzfeld was measured before each test using a photometer. The luminance of this adapting field could be reduced by either reducing the voltage across the lamp or introducing neutral or spectrally selective filters in the light path. The test light, which is $10 \mu \mathrm{s}$ in duration, was obtained from a Grass Instrument (Quincy, MA) strobe removed from its standard holder and mounted within a chamber on the ganzfeld above the subject's head. The light energy and/or spectral composition of this flash could also be changed by filters. The following Kodak Wratten (Rochester, NY) 19 (red, $633 \mathrm{~nm}$ nominal peak), 21 (yellow, $593 \mathrm{~nm}$ ), 61 (green, $534 \mathrm{~nm}$ ), 98 (blue, $450 \mathrm{~nm}$ ) and neutral density filters of various strengths were used. ERGs were recorded in the artefact reject mode and with a band pass of 5-1000 Hz. Cone ERG responses were obtained successively using white and red light at $5.1 \mathrm{~Hz}$ stimulus frequency and at least 500 responses were averaged. Rod ERGs were recorded using a $1.1 \mathrm{~Hz}$ blue flash stimulus after 3-5 minutes in the dark, according to a protocol which has previously been standardised in normal subjects.

Measurements of the ERG values were performed by a masked observer who did not know the side of the vein occlusion. Cone and rod b-wave amplitudes were measured from the trough of the a-wave to the peak of the b-wave in the affected and unaffected eyes. The b-wave implicit time was measured from the flash to the positive peak (b-wave) response. Cone ERG subnormality to red was defined as a bwave amplitude lower in the affected compared with the unaffected eye (ratio $<1)$. Patients' follow-up was obtained either by re-examining the patient and reviewing the medical chart $(n=16)$ or by contacting the referring physician and obtaining a detailed report $(n=5)$. At the time of follow-up, presence of either anterior or posterior segment neovascularisation, and whether the patient had undergone laser photocoagulation or cyclocryotherapy for ocular neovascularisation secondary to CRVO, were recorded.

In the statistical analysis, Student's and paired $t$-tests were used to compare ERG values in the affected with the unaffected eyes and in eyes with and without neovascularisation. Fisher's exact test was used to determine whether cone subnormality to red was significantly associated with the development of ocular neovascularisation. All $p$ values are twotailed.

\section{RESULTS}

Table I shows demographic and ERG data for the 21 patients (11 women and 10 men) included in the study. Fourteen were Caucasian, three AfricanAmerican and four Hispanic. The mean age of the patients was $64.0 \pm 18.6$ years (range $30-85$ years) (Table I). All patients had unilateral CRVO and a normal fellow eye. The mean length of time between diagnosis of the CRVO and follow-up examination was $25.7 \pm 16.1$ months (range 6-55 months). Three patients had open angle glaucoma, 7 had systemic hypertension and 1 had diabetes mellitus. Four patients from our own clinic underwent a second ERG test, 1 patient 1 month after the first ERG (patient 6), 1 patient 3 months later (patient 18), 1 patient 5 months later (patient 1 ), and 1 patient $2 \frac{1}{2}$ years later (patient 14) (Table I).

Table I shows that at follow-up, ocular neovascularisation had developed in $7(33 \%)$ patients, neovascular glaucoma in 6 and new vessels on the disc in 1 . We compared electroretinographic data in CRVO eyes with normal fellow eyes and in CRVO eyes with and without neovascularisation.

\section{Light-adapted Cone ERG Responses to Red Flash}

Compared with normal fellow eyes, cone ERG bwave responses to red flash in CRVO eyes showed significantly longer implicit time $(28.3 \pm 3.3 \mathrm{~ms}$ vs $25.1 \pm 2.4 \mathrm{~ms} ; t=5.25$, d.f. $=20, p<0.0001)$ and significantly higher amplitude $(6.9 \pm 4.8 \mu \mathrm{V}$ vs $5.1 \pm 3.4 \mu \mathrm{V} ; t=2.68$, d.f. $=20, p<0.01$ ) (Table II). At the time the first ERG was performed, 17 patients ( $81 \%)$ were supernormal to red in the CRVO eye compared with the fellow eye, and $4(19 \%)$ were subnormal. When all ERG test results (including the second ERG performed in 4 patients) are included, $15(71 \%)$ of the CRVO eyes were supernormal to red compared with fellow eyes, while $6(29 \%)$ were subnormal (Table I). At the time of follow-up, all 6 
Table I. Electroretinographic results

\begin{tabular}{|c|c|c|c|c|c|c|c|}
\hline \multirow[b]{2}{*}{ Patient no. } & \multirow[b]{2}{*}{ Age (years) } & \multirow[b]{2}{*}{ Sex } & \multirow[b]{2}{*}{ Follow-up ${ }^{\mathrm{a}}$ (months) } & \multicolumn{3}{|c|}{ Light-adapted b-wave to red $(\mu \mathrm{V} / \mathrm{ms})$} & \multirow[b]{2}{*}{ Neovascularisation } \\
\hline & & & & CRVO eye & Fellow eye & Ratio $^{\text {b }}$ & \\
\hline \multirow[t]{2}{*}{1} & 30 & $\mathrm{M}$ & 16 & $17.5 / 28.8$ & $13.3 / 24.8$ & 1.3 & 0 \\
\hline & & & & $7.3 / 29.6$ & $4.5 / 26.0$ & 1.6 & 0 \\
\hline 2 & 76 & $\mathrm{M}$ & 53 & $5.2 / 32.0$ & $1.8 / 25.6$ & 2.9 & + \\
\hline 3 & 68 & $\mathrm{~F}$ & 31 & $6.3 / 26.0$ & $5.7 / 24.4$ & 1.1 & 0 \\
\hline 4 & 83 & $\mathrm{~F}$ & 18 & $17.4 / 26.8$ & $8.0 / 24.8$ & 2.2 & 0 \\
\hline 5 & 67 & $\mathrm{M}$ & 7 & $5.8 / 31.8$ & $8.3 / 24.4$ & 0.7 & + \\
\hline \multirow[t]{2}{*}{6} & 46 & M & 13 & $8.4 / 24.8$ & $3.8 / 24.4$ & 2.2 & 0 \\
\hline & & & & $3.4 / 29.6$ & $4.6 / 23.2$ & 0.7 & + \\
\hline 7 & 83 & $\mathrm{~F}$ & 55 & $1.8 / 28.2$ & $2.2 / 25.0$ & 0.8 & + \\
\hline 8 & 78 & $\mathrm{~F}$ & 30 & $6.3 / 28.8$ & $3.9 / 26.8$ & 1.6 & 0 \\
\hline 9 & 70 & $\mathrm{~F}$ & 6 & $10.2 / 33.2$ & 2.3/29.2 & 4.4 & 0 \\
\hline 10 & 85 & $\mathrm{~F}$ & 12 & $2.1 / 27.2$ & $2.1 / 31.6$ & 1.0 & 0 \\
\hline 11 & 85 & $\mathrm{~F}$ & 12 & $5.1 / 32.3$ & $9.5 / 26.4$ & 0.5 & + \\
\hline 12 & 31 & $\mathrm{M}$ & 43 & $16.8 / 30.9$ & $12.3 / 23.1$ & 1.4 & 0 \\
\hline 13 & 77 & $\mathrm{~F}$ & 16 & $5.7 / 28.4$ & $4.6 / 24.8$ & 1.2 & 0 \\
\hline \multirow[t]{2}{*}{14} & 66 & $\mathrm{~F}$ & 39 & $0.8 / 20.3$ & $0.4 / 19.5$ & 2.0 & 0 \\
\hline & & & & $1.6 / 29.8$ & $2.0 / 27.6$ & 0.8 & + \\
\hline 15 & 52 & $\mathrm{M}$ & 41 & $8.0 / 24.4$ & $4.6 / 22.8$ & 1.7 & 0 \\
\hline 16 & 79 & M & 41 & $6.3 / 27.6$ & $5.8 / 24.4$ & 1.1 & 0 \\
\hline 17 & 72 & $\mathrm{~F}$ & 41 & $3.0 / 30.4$ & $3.4 / 26.8$ & 0.9 & + \\
\hline \multirow[t]{2}{*}{18} & 30 & $\mathrm{M}$ & 10 & $4.8 / 24.8$ & $3.9 / 23.2$ & 1.2 & 0 \\
\hline & & & & $5.9 / 24.0$ & $4.8 / 23.2$ & 1.2 & 0 \\
\hline 19 & 42 & M & 12 & $6.2 / 25.2$ & $5.0 / 24.0$ & 1.2 & 0 \\
\hline 20 & 69 & M & 36 & $3.3 / 30.4$ & $1.8 / 25.6$ & 1.8 & 0 \\
\hline 21 & 56 & $\mathrm{~F}$ & 8 & $4.8 / 32.0$ & $4.3 / 26.4$ & 1.1 & 0 \\
\hline
\end{tabular}

${ }^{a}$ Time from diagnosis to follow-up examination.

${ }^{b}$ Ratio of b-wave amplitude to red flash in the CRVO eye to that in the fellow eye.

Neovascularisation: 0 , none; + , present.

$(100 \%)$ patients with subnormality to red in the CRVO eye compared with the fellow eye had developed ocular neovascularisation, compared with $1(7 \%)$ of the 15 patients with supernormality in the CRVO eye (Fisher's exact, $p=0.00013$ ).

There was no association between quantity of intraretinal haemorrhages and cone ERG responses to red flash. Fig. 1 shows an example of subnormality of the light-adapted cone ERG to red flashes in one patient with unilateral CRVO. Fig. 2 shows the most typical example of supernormality of the lightadapted cone ERG response to red flash in one patient. The responses to all other wavelengths, including the rod responses, are subnormal in the CRVO eye. The b-wave of the cone and rod responses is delayed in the CRVO eye to all stimuli.

\section{Light-adapted Cone ERG Responses to White Flash}

Compared with normal fellow eyes, eyes with CRVO had a significantly longer cone $b$-wave implicit time response to white flash $(30.5 \pm 3.9 \mathrm{~ms}$ vs $27.5 \pm 2.7 \mathrm{~ms} ; t=4.6$, d.f. $=20, p<0.001)$ (Table II). Cone b-wave amplitudes were not significantly different between eyes, although the mean amplitude is lower in CRVO eyes compared with unaffected eyes.

CRVO eyes which subsequently developed ocular neovascularisation had significantly longer implicit time $(34.4 \pm 2.9 \mathrm{~ms}$ vs $29.7 \pm 3.1 \mathrm{~ms} ; t=3.27$, d.f. $=19, p<0.01$ and significantly lower amplitude $(28.5 \pm 9.2 \mu \mathrm{V}$ vs $65.3 \pm 31.3 \mu \mathrm{V} ; t=3.01$, d.f. $=19$, $p<0.01)$ cone $b$-wave responses to white flash than
CRVO eyes without neovascularisation. However, there was an overlap of $95 \%$ confidence limits for both implicit time and amplitude for CRVO eye with and without neovascularisation.

\section{Rod ERG Responses to Blue Flash}

In 19 to 21 patients rod ERG responses to blue flash were available. Compared with normal fellow eyes, rod b-wave ERG responses in the CRVO eyes showed significantly longer implicit time $(53.2 \pm 9.4$ ms vs $47.2 \pm 6.1 \mathrm{~ms} ; t=4.79$, d.f. $=17, p<0.001)$ and significantly lower amplitudes $(24.6 \pm 18.5 \mu \mathrm{V}$ vs $56.4 \pm 35.8 \mu \mathrm{V} ; t=5.1$, d.f. $=18, p<0.001)$ (Table II).

Implicit time of the rod ERG b-wave was significantly longer in CRVO eyes with subsequent

Table II. ERG values in CRVO and normal fellow eyes

\begin{tabular}{|c|c|c|c|}
\hline ERG parameter & CRVO eye & Normal fellow eye & $p$ \\
\hline \multicolumn{4}{|l|}{ Cone b-wave } \\
\hline Amplitude $(\mu \mathrm{V})$ & $58.9 \pm 34.2$ & $65.8 \pm 29.4$ & \\
\hline Implicit time (ms) & $30.5 \pm 3.9$ & & $p<0.001$ \\
\hline \multicolumn{4}{|l|}{$\operatorname{Red}(n=21)$} \\
\hline Amplitude $(\mu \mathrm{V})$ & $6.9 \pm 4.8$ & $5.1 \pm 3.4$ & $p<0.01$ \\
\hline Implicit time (ms) & $28.3 \pm 3.3$ & $25.1 \pm 2.4$ & $p<0.0001$ \\
\hline \multicolumn{4}{|l|}{ Rod b-wave $(n=19)$} \\
\hline Amplitude $(\mu \mathrm{V})$ & $24.6 \pm 18.5$ & $56.4 \pm 35.8$ & $p<0.001$ \\
\hline Implicit time (ms) & $53.2 \pm 9.4$ & $47.2 \pm 6.1$ & $p<0.001$ \\
\hline \multicolumn{4}{|c|}{$\begin{array}{l}\text { Compared with normal fellow eyes, CRVO eyes had a } \\
\text { significantly longer implicit time of cone b-wave to white } \\
(t=4.60 \text {, d.f. }=20, p<0.001) \text {, higher amplitude and longer } \\
\text { implicity time of the cone b-wave to red }(r=2.68 \text {, d.f. }=20 \text {, } \\
p<0.01 \text { and } t=5.25, \text { d.f. }=20, p<0.0001 \text { respectively) and lower } \\
\text { amplitude and longer implicit time of the rod b-wave to blue } \\
(t=5.10 \text {, d.f. }=18, p<0.001 \text { and } t=4.79 \text {, d.f. }=17, p<0.001 \\
\text { respectively). }\end{array}$} \\
\hline
\end{tabular}




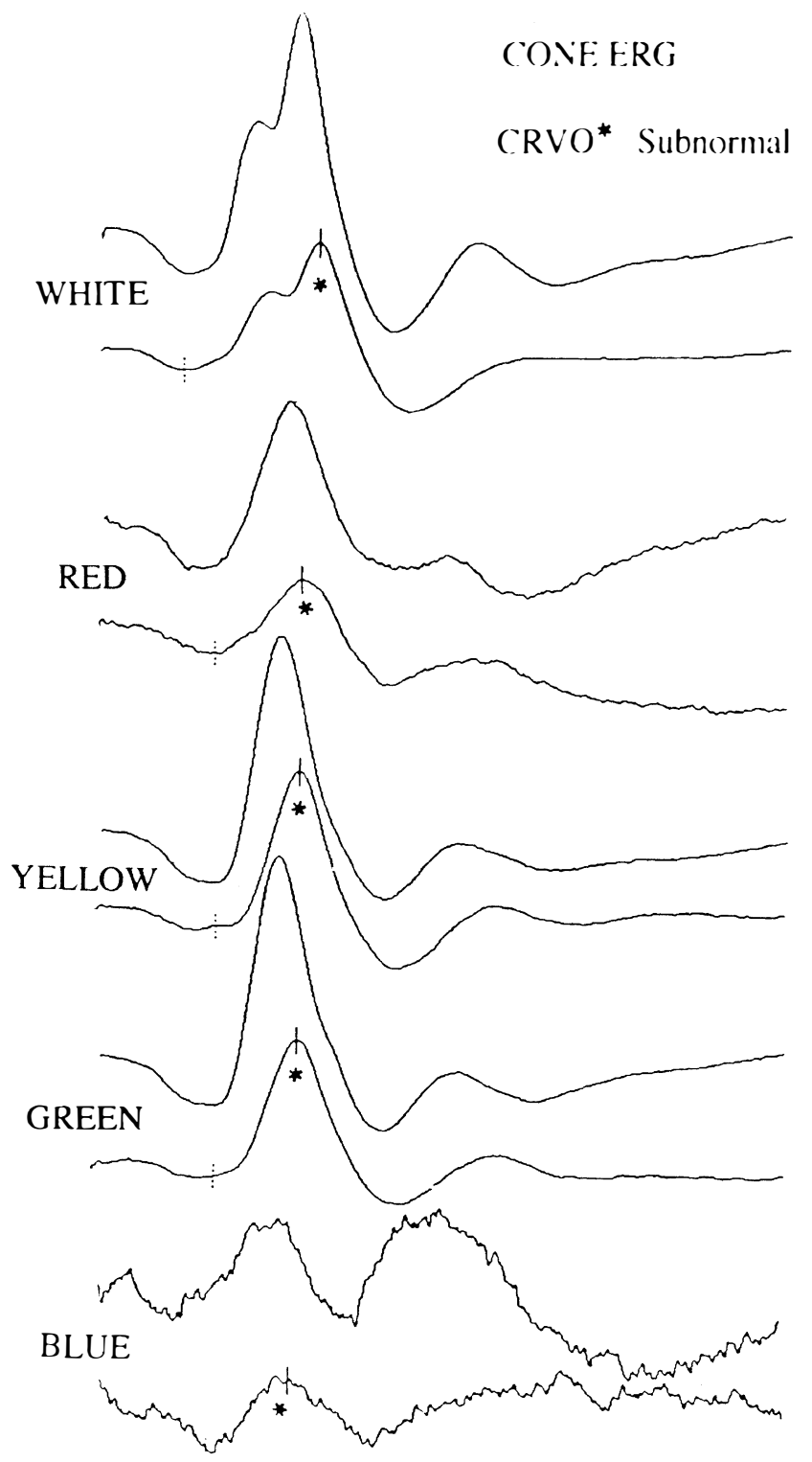

Fig. 1. The light-adapted cone ERG subnormality to red flashes in one patient who had CRVO in the left eye (asterisk) and later developed neovascular glaucoma in that eye. Each trace is $100 \mathrm{~ms}$ in duration.

neovascularisation than in those which did not develop ocular neovascularisation $(60.9 \pm 11.1 \mathrm{~ms}$ vs $50.2 \pm 6.3 \mathrm{~ms} ; t=2.92$, d.f. $=16, p<0.01)$. However, again there was an overlap of $95 \%$ confidence limits for these two groups. There were no significant differences between these two groups for amplitude of the rod b-wave.

\section{DISCUSSION}

In the present study we confirmed our hypothesis that subnormality of the cone ERG b-wave response to red flash in CRVO eyes compared with normal fellow eyes is associated with later development of ocular neovascularisation. In the 4 patients who were subnormal on initial ERG testing, neovascular glaucoma subsequently developed. In the 2 patients

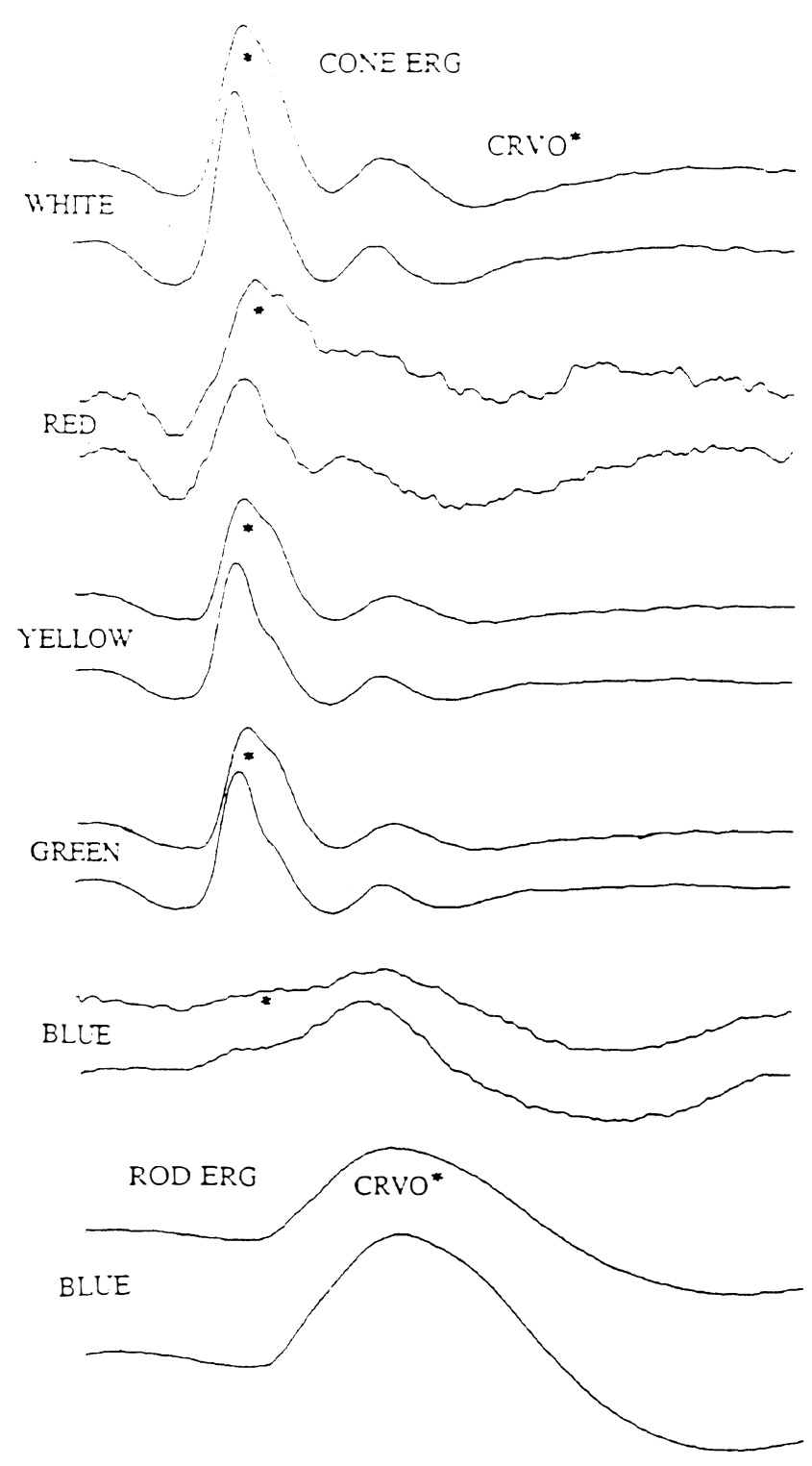

Fig. 2. The light-adapted cone (upper five sets) and the dark-adapted (lowest set) ERG responses. The cone ERG is shown to five different spectral stimuli: white, red $(653 \mathrm{~nm})$, yellow $(593 \mathrm{~nm})$, green $(534 \mathrm{~nm})$ and blue $(450 \mathrm{~nm})$. Compared with the normal fellow eye, only the cone ERG to red is supernormal in the CRVO eye (asterisk). For all other wavelengths, the ERG of the CRVO eye is subnormal. Each trace is $100 \mathrm{~ms}$ in duration.

who showed supernormality on the first ERG test, but became subnormal on a second ERG test, ocular neovascularisation also subsequently developed. The only patient who was supernormal to red at the time the CRVO was diagnosed and later developed new vessels on the optic disc and iris did not undergo any other ERG testing. Thus, we do not know whether the eye had then become subnormal to red.

Our data suggest that cone ERG subnormality to red flash in eyes with unilateral CRVO (when compared with normal fellow eyes) may be a predictor of later ocular neovascularisation. Initial ERG cone supernormality to red, however, may not 


\section{CONE ERG}

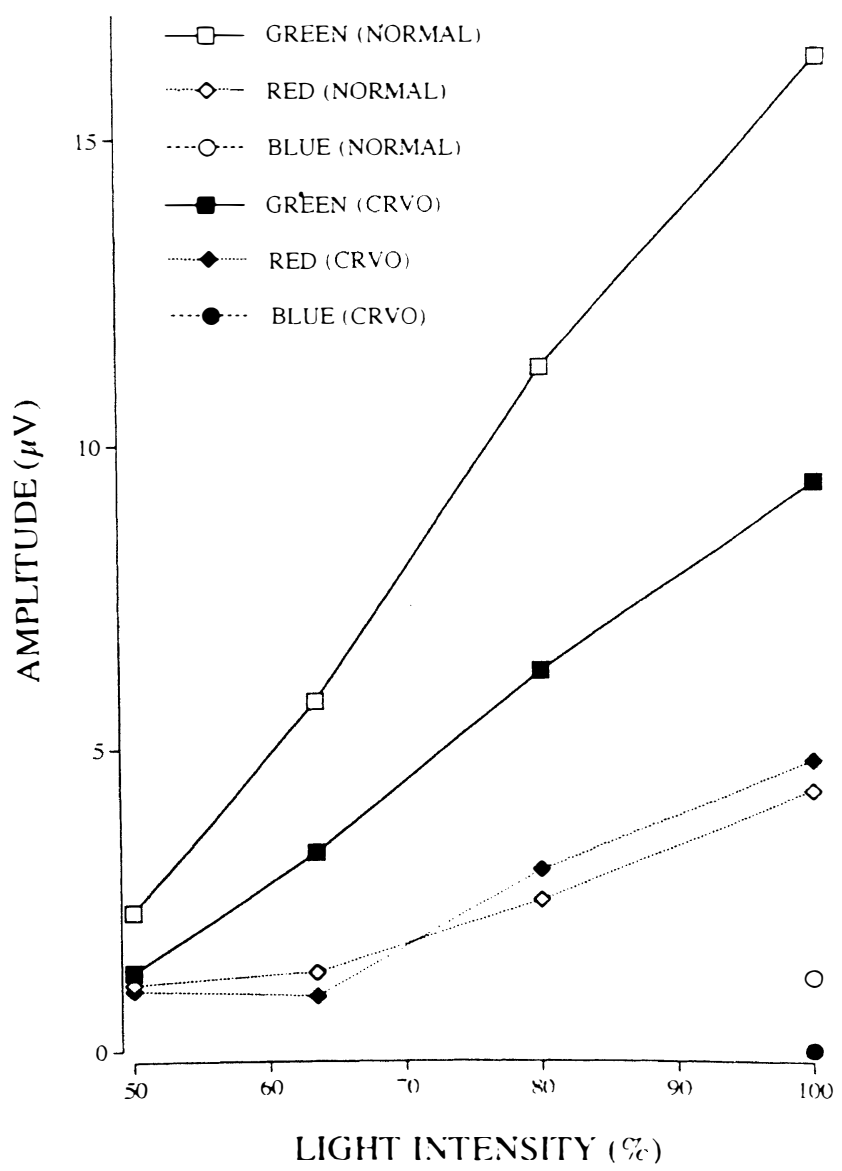

Fig. 3. The relationship between cone b-wave amplitude and flash intensity in relative units in a linear scale. There is an approximate linear relationship between these two variables in the strongly light-adapted retina. This relationship is shown for three different wavelengths: green $(534 \mathrm{~nm})$, red $(633 \mathrm{~nm})$ and blue $(450 \mathrm{~nm})$. Only one data point was obtainable to blue. Compared with the normal fellow eye, the responses to green and blue are smaller in the $C R V O$ eye but the response to red is larger. This result can only be explained by a shift in the action spectrum of the cone ERG to longer wavelengths.

be 'protective' against later development of ocular neovascularisation, since two of the supernormal CRVO eyes which had a second ERG test subsequently lost this supernormality, and were then found to have developed neovascularisation when the follow-up was done. This is in agreement with previous reports that $10 \%$ of eyes with nonischaemic CRVO at the time of diagnosis may have a second occlusion and later become ischaemic. ${ }^{1}$

In the 5 patients in whom fluorescein angiography was obtained, cone ERG supernormality to red was present in the CRVO eye compared with the normal fellow eye and was associated with good retinal capillary perfusion. In CRVO eyes, retinal capillary non-perfusion involving more than 10 disc areas of the fundus on fluorescein angiography has been used to predict ocular neovascularisation..$^{18}$ Fluorescein angiography features, however, are often difficult to interpret early in the disease process because of the presence of deep intraretinal haemorrhages and oedema. ${ }^{5}$ In the present study, there was no association between the quantity of intraretinal haemorrhages and a ERG responses to red flash.

Cone supernormality in CRVO can be quite specific for long wavelengths, as shown in Fig. 3 where cone ERG responses to various wavelengths were obtained in one patient. Fig. 3 shows that cone b-wave amplitude increases with increasing light intensity in an approximately linear way. Compared with the normal fellow eye, responses in the CRVO eye are smaller to green and blue light and as large or larger to red light. Thus, in CRVO eyes responsitivity is greater to red and less to green and blue. This supernormality in CRVO eyes is unexpected. In fact, ERG data in patients with CRVO show decreased b-wave amplitudes, ${ }^{13-15,18,20-22}$ and supernormal ERG responses have rarely been reported. ${ }^{11}$

In the present study, CRVO eyes with neovascularisation compared with eyes without showed significantly longer implicit time and lower amplitudes of the cone b-wave ERG responses to white flash (Table II). However, neither of these two ERG parameters could separate with $95 \%$ confidence CRVO eyes with neovascularisation from those without. This is in contrast to Kaye and Harding's ${ }^{16}$ finding that prolongation of $b$-wave implicit time allows separation of rubeotic from non-rubeotic eyes with $99 \%$ confidence.

In the present study we also found that CRVO eyes with neovascularisation had significantly longer rod b-wave implicit time than eyes without neovascularisation. However, confidence limits of this ERG parameter for the two groups overlap at the $95 \%$ level and, thus, do not completely separate eyes with neovascularisation from those without. Similarly, a b/a-wave amplitude ratio to single white flash darkadapted ERG of less than 1 has been shown to be an indicator of subsequent ocular neovascularisation. ${ }^{17,18}$ In the study by Sabates et al. ${ }^{18}$ retinal ischaemia was determined from the clinical and fluorescein angiographic features in the CRVO eye. Seven patients with a b/a ratio $<1$ did not receive laser photocoagulation, and were thus available for follow-up. Four (57\%) of these 7 patients developed neovascular glaucoma. In contrast in our study, all patients with ERG subnormality to red in the CRVO eyes compared with normal fellow eyes subsequently developed ocular neovascularisation.

Reduction in amplitude of the maximum ERG dark-adapted response $\left(R_{\max }\right)$ in CRVO eyes is another parameter reported as a predictor of subsequent ocular neovascularisation. ${ }^{15}$ This 
parameter was subsequently shown by other investigators to have a false positive rate of $14 \% .{ }^{18}$ Since we do not use a similar ERG protocol, it is difficult for us to examine this particular factor. Similarly, we have not looked for absence of oscillatory potentials (a sign of inner retinal ischaemia) as a predictor of ocular neovascularisation. ${ }^{23}$

Cone ERG supernormality to red in CRVO eyes compared with normal fellow eyes suggests that there is a shift in the action spectrum of the cone response towards longer wavelengths. A possible explanation for this shift is an increase in chloride concentration in the CRVO retina, since it is known that the absorption spectrum of the long (L) and middle $(\mathrm{M})$ wave length cone pigments will shift to longer wavelengths if the chloride concentration is high. ${ }^{24}$ It is thought that this is due to a histidine binding site $\left(\mathrm{His}^{197}\right)$ located on the extracellular side of the cone outer segment membrane. ${ }^{25} \mathrm{CRVO}$ eyes with ERG subnormality to red may have low extracellular chloride levels.

This subnormality of the light-adapted cone ERG to red stimuli response appears to be a sensitive parameter to detect eyes which may be at risk for later development of neovascularisation. However, it is important to appreciate that the light-adapted cone ERG to red is only about $5 \mu \mathrm{V}$ and, thus, impossible to detect without averaging or with less sensitive systems than the Nicolet ERG system used in the present study. Identification of subnormality to red also depends on comparing the CRVO eye with the normal fellow eye and thus cannot be used when there is either bilateral CRVO or any other abnormality of the fellow eye.

In summary, the results of the present study suggest that cone ERG subnormality to longwavelength (red) flashes in eyes with unilateral CRVO compared with normal fellow eyes at the time of diagnosis of the vein occlusion may be an indicator of subsequent development of ocular neovascularisation. Clinicians may still follow the current clinical practice of initiation of laser photocoagulation in CRVO eyes only when ocular neovascularisation develops. However, ERG subnormality to red in CRVO eyes may justify particularly close follow-up of those patients. Larger prospective studies of patients with CRVO are in progress.

Key words: Electroretinogram, ERG, Occlusion, Retinal vein, Subnormality

\section{REFERENCES}

1. Hayreh SS. Classification of central retinal vein occlusion. Ophthalmology 1983;90:458-74.

2. Hayreh SS, Hayreh MS. Hemicentral retinal vein occlusion: pathogenesis, clinical features and natural history. Arch Ophthalmol 1980;98:1600-9.
3. Hayreh SS, Rojas P, Podhajsky P, Montague P, Woolson RF. Ocular neovascularisation with retinal vascular occlusion. III. Incidence of ocular neovascularisation with retinal vein occlusion. Ophthalmology 1983;90:488-506.

4. Magargal LE, Donoso LA, Sanborn GE. Retinal ischemia and risk of neovascularisation following central retinal vein obstruction. Ophthalmology 1982; 89:1241-5.

5. Laatikainen L, Kohner EM. Fluorescein angiography and its prognostic significance in central retinal vein occlusion. Br J Ophthalmol 1976;60:411-8.

6. Laatikainen L, Kohner EM, Khoury D, Black RK. Panretinal photocoagulation in central retinal vein occlusion: a randomised controlled clinical study. Br J Ophthalmol 1977;61:741-53.

7. Magargal LE, Brown GC, Augsburger JJ, Donoso LA. Efficacy of panretinal photocoagulation in preventing neovascular glaucoma following ischemic central retinal vein obstruction. Ophthalmology 1982;89:780-4.

8. May DR, Klein ML, Peyman GA, Raichand M. Xenon panretinal photocoagulation for central retinal vein occlusion: a randomised prospective study. $\mathrm{Br} \mathrm{J}$ Ophthalmol 1979;63:725-34.

9. Murdoch IE, Rosen PH, Shilling JS. Neovascular response in ischemic central retinal vein occlusion after panretinal photocoagulation. $\mathrm{Br} \mathrm{J}$ Ophthalmol 1991;75:459-61.

10. Tasman W, Magargal LE, Augsburger JJ. Effects of argon laser photocoagulation on rubeosis iridis and angle neovascularisation. Ophthalmology 1980;87: 400-2.

11. Hayreh SS, Klugman MR, Beri M, Kimura AE, Podhajsky P. Differentiation of ischemic from nonischemic central retinal vein occlusion during the early acute phase. Graefes Arch Clin Exp Ophthalmol 1990;228:201-17.

12. Sinclair SH, Gragoudas ES. Prognosis for rubeosis iridis following central retinal vein occlusion. $\mathrm{Br} \mathrm{J}$ Ophthalmol 1979;63:735-43.

13. Breton ME, Quinn GE, Keene SS, Dahmen JC, Brucker AJ. Electroretinogram parameters at presentation as predictors of rubeosis in central retinal vein occlusion patients. Ophthalmology 1989;96:1343-52.

14. Hayreh SS, Klugman MR, Podhajsky P, Kolder HE. Electroretinopathy in central retinal vein occlusion: correlation of electroretinographic changes with pupillary abnormalities. Graefes Arch Clin Exp Ophthalmol 1989;227:549-61.

15. Johnson M, Marcus S, Elman MJ, McPhee TJ. Neovascularisation in central retinal vein occlusion: electroretinographic findings. Arch Ophthalmol 1988; 106:348-52.

16. Kay SB, Harding SP. Early electroretinography in unilateral central retinal vein occlusion as a predictor of rubeosis iridis. Arch Ophthalmol 1988;106:353-6.

17. Matsui Y, Katsumi O, MacMeel JW, Hirose T. Prognostic value of initial electroretinogram in central retinal vein obstruction. Graefes Arch Clin Exp Ophthalmol 1994;232:75-81.

18. Sabates R, Hirose T, MacMeel JW. Electroretinography in the prognosis and classification of central retinal vein occlusion. Arch Ophthalmol 1983;101:232-5.

19. Gouras P, MacKay CJ. Supernormal cone electroretinogram in central retinal vein occlusion. Invest Ophthalmol Vis Sci 1992;33:508-15. 
20. Henkes HE. Electroretinography in circulatory disturbances of the retina. I. Electroretinogram in cases of occlusion of central retinal vein or of one of its branches. Arch Ophthalmol 1953;51:190-201.

21. Morrell AJ, Thompson DA, Gibson JM, Kritzinger EE, Drasdo N. Electroretinography as a prognostic indicator of neovascularisation in CRVO. Eye 1991; 5:362-8.

22. Karpe G, Germanis M. The prognostic value of the electroretinogram in thrombosis of the retinal veins. Acta Ophthalmol Suppl 1962;70:202-9.
23. Bresnick GH, Korth K, Groo A. Electroretinographic oscillatory potentials predict progression of diabetic retinopathy: preliminary report. Arch Ophthalmol 1984;102:1307-11.

24. Crescitelli F, Karvaly B. The Gecko Visual Pigments: the anion hypsochromic effect. Vision Res 1991;31: 945-50.

25. Wang Z, Asenjo AB, Prian DD. Identification of the CI-binding site in the human red and green colour vision pigments. Biochemistry 1993;32:2125. 